\title{
RADIOLYTIC GAS GENERATION IN SALT CAKE TECHNICAL TASK PLAN (U)
}

by

D. D. Walker

Westinghouse Savannah River Company

Savannah River Site

Aiken, South Carolina 29808

This paper was prepared in connection with work done under the above contract number with the U.S.

Department of Energy. By acceptance of this paper, the publisher and/or recipient acknowledges the U.S.

Government's right to retain a nonexclusive, royalty-free license in and to any copyright covering this paper, along with the right to reproduce and to authorize others to reproduce all or part of the copyrighted paper. 


\section{DISCLAIMER}

This report was prepared as an account of work sponsored by an agency of the United States Government. Neither the United States Government nor any agency thereof, nor any of their employees, makes any warranty, express or implied, or assumes any legal liability or responsibility for the accuracy, completeness, or usefulness of any information, apparatus, product, or process disclosed, or represents that its use would not infringe privately owned rights. Reference herein to any specific commercial product, process, or service by trade name, trademark, manufacturer, or otherwise does not necessarily constitute or imply its endorsement, recommendation, or favoring by the United States Government or any agency thereof. The views and opinions of authors expressed herein do not necessarily state or reflect those of the United States Government or any agency thereof.

This report has been reproduced directly from the best available copy.

Available to DOE and DOE contractors from the Office of Scientific and Technical Information, P. O. Box 62, Oak Ridge, TN 37831; prices available from (615) 576-8401.

Available to the public from the National Technical Information Service, U. S. Department of Commerce, 5285 Port Royal Rd., Springfield, VA 22161 
Keywords: High activity liquid waste, saltcakes, hydrogen

Retention time: Permanent

August 29, 1993

TO: S. D. FINK, 773-A

FROM: D. D. WALKER, 773-A, C. I. CRAFEORD, 773-A, and N. E. BIBLER, 773-A

RADIOLYTIC GAS GENERATION IN SALT CAKE TECHNICAL TASK PIAN (U)

\section{INTRODUCTION}

High-level radioactive wastes are stored in large, steel tanks in the Savannah River Site Tank Farms. The liquid levels in these tanks are monitored to detect leakage of waste out of tanks or leakage of liquids into the tanks. Recent unexplained level fluctuations in high-level waste (HLW) tanks have caused High Level Waste Engineering (HLWE) to develop a program to better understand tank level behavior. 1 Interim waste Technology (IWT) has been requested ${ }^{2}$ by HLWE to obtain data which will lead to a better understanding of the radiolytic generation of gases in salt cake. The task described below will provide data from laboratory experiments with simulated wastes which can be used in tank level fluctuation modeling.

\section{TASK DESCRIPTION}

\section{Task Deliverables}

IWT will provide HLWE a summary report of the results of all experiments.

\section{Task Requirements}

The requirements for this task are in the Technical Task Request received from HLWE. ${ }^{2}$ All experimental work shall be conducted in accordance with established Quality Assurance programs. ${ }^{3}$ HLWE agreement with the task activities and quality assurance controls is indicated by the signature of the Manager, HLWE Support, in the approval section of this document.

\section{Task Prerequisites}

None. 


\section{TASK ACTIVITIES}

The following experimental programs have been formulated to meet the task requirements of the customer:

A. Determine whether radiolytically generated gas bubbles can be trapped in salt cake.

Salt solutions with compositions reflecting the average composition of SRS high-level waste will be prepared. The solutions will be evaporated and allowed to crystalize to simulate salt cake deposits in waste tanks. The crystallized salt cake will be irradiated in Co-60 gamma sources to simulate the self-irradiation of real waste. Suitable irradiation containers will be fabricated so the detection of gas bubbles trapped in the salt cake is possible. Photographic records of the bubbles will be made. (Responsibility: D. D.Walker)

B. Determine the composition of gases produced by radiolysis.

Salt cake and solution samples will be prepared and irradiated by D. D. Walker as described above. The concentration of hydrogen and oxygen in the radiolysis gases will be measured by C. L. Crawford using gas chromatography (GC). The effect of waste composition (nitrate, nitrite, and water) on the composition of the gas will be determined. (Responsibility: D. D. Walker and C. L. Crawford)

c. Determine the yield of radiolysis gases as a function of radiation dose.

The rate of formation of trapped gases will be determined by measuring the amount of salt solution displaced from the salt cake. Doses up to $10 \mathrm{Mrad}$ (about 10 years of Tank Farm storage) will be studied. (Responsibility: D. D. Walker)

D. Determine bubble distribution.

The size, distribution, growth patterns, and ultimate trapped volume will be determined for doses up to 10 Mrad. Quantitative and photographic records will be made. (Responsibility:

D. D. Walker)

N. E. Bibler will provide technical oversight and advice, rut is not directly responsible for any activities. C. L. Crawford is assigned to the Defense waste processing Technology Section and the quality controls on his activities are described in the Glass Technology Procedures Manual, L13.1.

\section{CRITICAL MEASUREMENTS}

The experimental program to measure trapped gas production from radiolysis of damp salt cake requires the following critical measurements:

Salt solution and salt cake composition: All salt solutions will 
be prepared from reagent grade chemicals and the concentrations of major components verified by routine analyses performed by the Analytical Development section (ADS) of SRTC. Compositions of salt cake will be determined by redissolution in water and analysis by ADS. The error in routine ADS analytical measurements is $\pm 10 \% 195 \%$ confidence level). ADS activities shali be controlled in accordance with the ADS QA program. 4

Radiation Dose: Dose rates to samples irradiated in SRTC Co-60 gamma sources will be measured by Fricke dosimetry and nylon film dosimeters. 5

Gas Compositions: Gas compositions will be measured by gas chromatography (MT\&E\#IW-0037). The GC instrument will be calibrated with certified standard gas mixtures before use.

Time: Elapsed time will be measured using the wall clock in Lab B-103 (MT\&E \#IW-00020) or an equivalent replacement. The accuracy of this clock is maintained to within \pm 2 minutes using IWT Operating Procedure \#IWT-OP-008.

Mass: Simulated slurries will be made from reagent grade chemicals by weighing on calibrated balances (MT\&E\#WP-0003 or \#WP-0004). These balances are checked daily before use (Procedure \#IW-OP-11) with weights (MT\&E\#WP-800 or \#WP-823) calibrated at the SRTC Standards Laboratory.

\section{SAFETY}

The experimental work in this task does not require significant modifications to any SRTC safety-related laboratory systems. This task does not introduce any new safety hazards nor does it significantly increase previous chemical and radiological safety hazards. Small volumes $(<5 \mathrm{~L})$ of strongly alkaline salt solutions and salt cakes will be prepared. Portions of the salt solutions and cakes $(<1 \mathrm{~L})$ will be irradiated in the Co-60 sources, producing small amounts $(<0.5 \mathrm{~L} / \mathrm{sample})$ of gaseous decomposition products. Pressures developed in small, sealed containers will be less than 14 psig. No new safety or waste handling procedures are required.

\section{DOCUMENTATION}

All experimental instructions, results, and calculations will be recorded in official laboratory notebooks (WSRC-NB-xx-xxx).

D. D. Walker and C.L. Crawford will maintain separate notebooks; N. E. Bibler will not require a notebook. All significant results will be documented in numbered WSRC technical reports

(WSRC-RP- $x x-x \times x$ ) with permanent lifetimes. Preliminary results will be documented, when deemed necessary by the researcher and his supervision, in numbered memoranda (SRT-LWP- $x \mathrm{x}-\mathrm{x} \times \mathrm{x}$ ). 
S. D. FINK

\section{REFERENCES}

1. J. E. Marra, "Tank Level Program Action Plan (U), "
HLW-HLE-931291, Rev.0, August 31, 1993 .

2. J. E. Marra, Technical Task Request HLE-TTR-93077.

3. DWP \& HT Quality Assurance Procedures Manual, 1043.

4. a. Analytical Development Section, QA Implementation Manual, 1Q31-3.

b. Analytical Development Section, Analytical operating 5. N. E. Bibler, "Calibration of Intense Co-60 Gamma Ray Sources
at the Savannah River Plant," DP-1414, May, 1976.

\section{APPROVALS}

$\frac{0.1 . \$ C_{7}}{\text { IWT Technical Review }} \frac{10-11-53}{\text { Date }}$
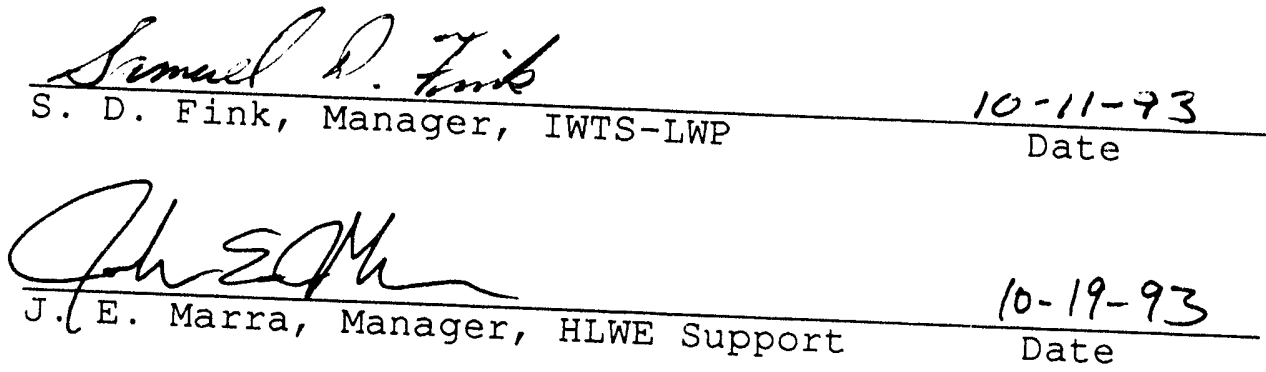

CC :

P. E. Lowe, 773-42A

L. M. Nelson, 773-43A

IWT-LWP Files, 773-A

TIM, 773-52A (4) 


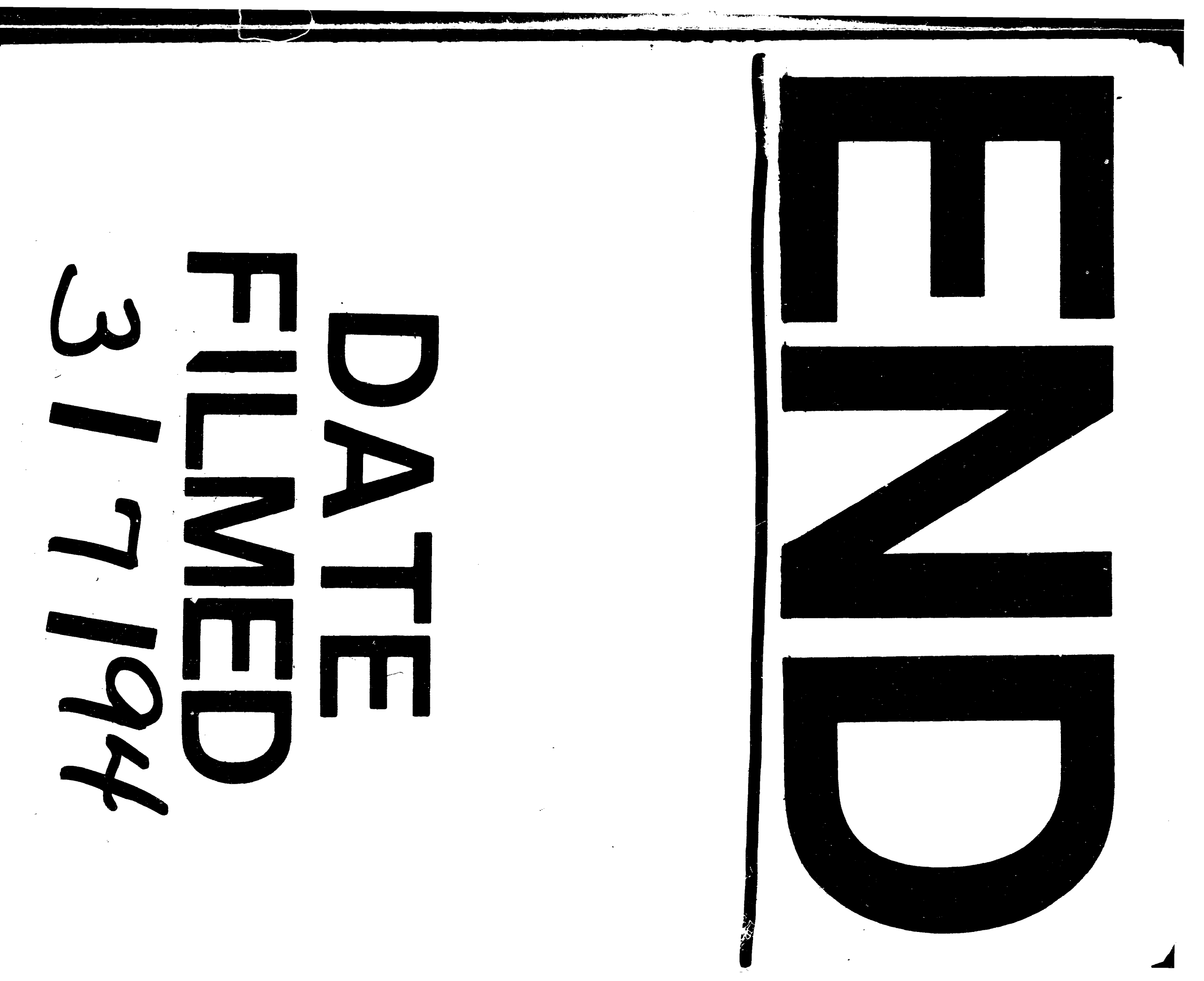


